\title{
O Dito e o Não Dito na Educação Sexual: Uma Produção Discursiva
}

What is Said and What is Unsaid in Sexual Education:

A Discourse Production

Lo Dicho y Lo no Dicho en la Educación Sexual: Una Producción Discursiva

Eugênia Marques de Oliveira Melo

Núcleo Paradigma de Análise do Comportamento - São Paulo

Débora Pinho Arruda Universidade Veiga de Almeida

Helenira Fonseca de Alencar $\&$ Veriana de Fátima Rodrigues Colaço Universidade Federal do Ceará
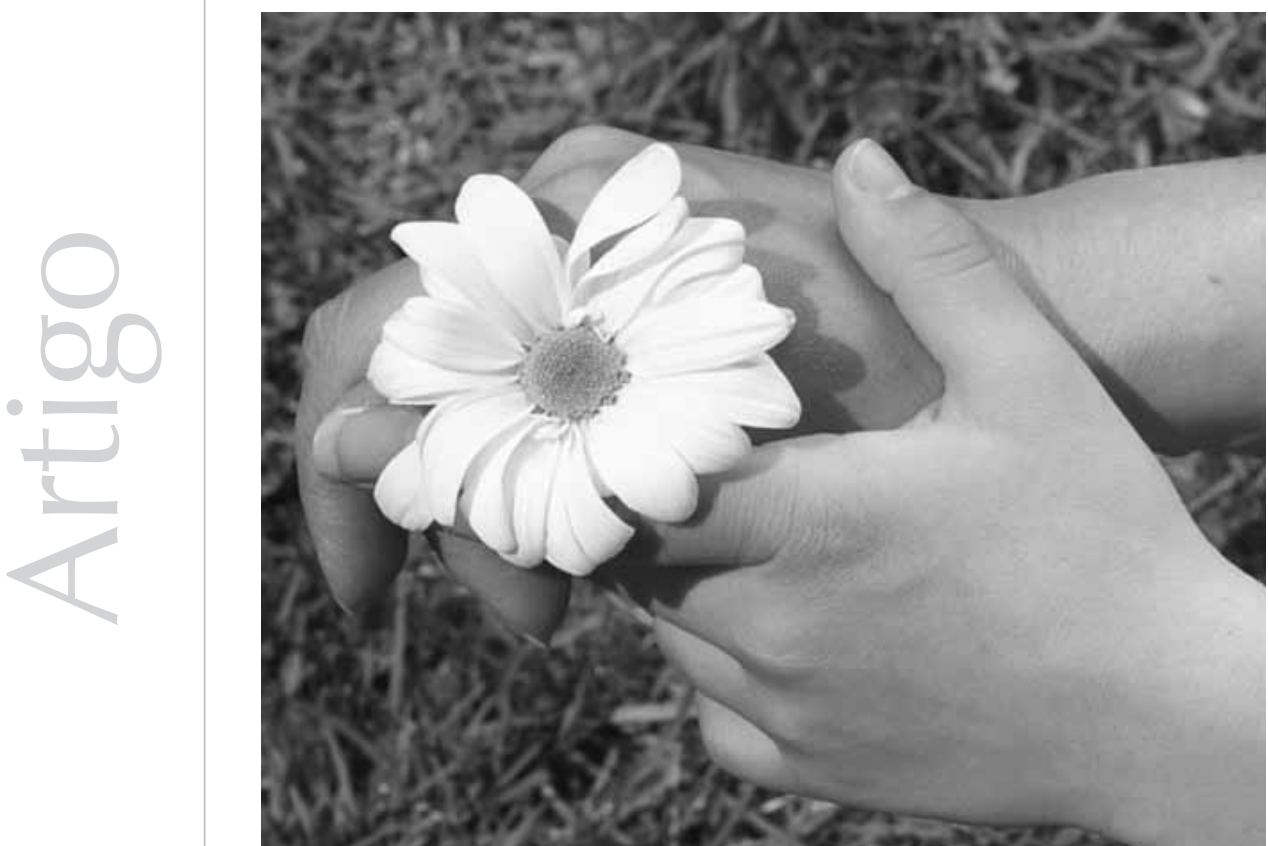
Resumo: Este artigo advém de uma pesquisa na qual investigamos como o discurso sobre a sexualidade é produzido nas escolas religiosas e laicas na contemporaneidade na cidade de Fortaleza. Tendo em vista possíveis influências religiosas e políticas sobre os discursos produzidos nessas escolas acerca do tema educação sexual, objetivamos investigar as possíveis diferenças entre elas bem como o dispositivo de podersaber-prazer existente nos discursos analisados. Para isso, utilizamos uma perspectiva foucaultiana, que enfatiza as produções discursivas, investigando as relações de poder que perpassam seus enunciados e seu poder de disciplinamento social. A pesquisa foi realizada em quatro escolas de Fortaleza: duas laicas (uma pública e uma particular) e duas religiosas, uma protestante e outra católica. Entrevistamos três diretores e quatro coordenadores pedagógicos do ensino fundamental II, buscando incitar as produções discursivas presentes no contexto educacional acerca da concepção da educação sexual. Utilizamos o método qualitativo baseado no construcionismo social, com mapas de associação de ideias a partir dos quais elaboramos categorias analíticas e realizamos análises da produção dos sentidos. Percebemos diferenças nos discursos acerca da educação sexual entre as escolas religiosas e laicas e semelhança entre as escolas religiosas em relação à forma como o corpo é abordado.

Palavras-chave: Análise do discurso. Educação sexual. Escolas de primeiro grau. Foucault.

Abstract: This article comes from a research through which we investigated how the speech about sexuality is produced in religious and laic schools in the current days in the city of Fortaleza. Considering possible religious and political influences over the speeches produced in these schools about the topic of sexual education, we aimed to investigate the possible differences between them as well as Foucault's power/ knowledge/pleasure combination present in the analyzed speeches. To do so, we used Foucault's perspective, since it highlights the discourse productions in the investigation of the power relationships which bypass their principles and their power of social disciplining. The research was conducted in four schools in Fortaleza: two secular schools (a public one and a private one) and two religious schools (a protestant and a catholic). We have interviewed three elementary school principals and four coordinators in order to ignite discourse productions about the conception of sexual education. As methodological procedure we used the qualitative method based on social constructionism, with the formulation of maps of association of ideas, from which we developed analytical categories and performed the analysis of the production of senses. Differences in the discourses about sexual education between the religious and laic schools and similarities among the religious schools regarding the way the body is discussed were noticed.

Keywords: Discourse analysis. Sexual education. Elementary school. Foucault.

Resumen: Este artículo adviene de una pesquisa en la cual investigamos cómo el discurso sobre la sexualidad es producido en las escuelas religiosas y laicas en la contemporaneidad en la ciudad de Fortaleza. Teniendo en vista posibles influencias religiosas y políticas sobre los discursos producidos en esas escuelas acerca del tema educación sexual, objetivamos investigar las posibles diferencias entre ellas así como el dispositivo de poder-saber-placer existente en los discursos analizados. Para eso, utilizamos una perspectiva foucaultiana, que enfatiza las producciones discursivas, investigando las relaciones de poder que exceden sus enunciados y su poder de disciplinado social. La pesquisa fue realizada en cuatro escuelas de Fortaleza: dos laicas (una pública y una particular) y dos religiosas, una protestante y otra católica. Entrevistamos a tres directores y a cuatro coordinadores pedagógicos de la enseñanza fundamental II, buscando incitar las producciones discursivas presentes en el contexto educacional acerca de la concepción de la educación sexual. Utilizamos el método cualitativo basado en el construccionismo social, con mapas de asociación de ideas a partir de los cuales elaboramos categorías analíticas y realizamos análisis de la producción de los sentidos. Percibimos diferencias en los discursos acerca de la educación sexual entre las escuelas religiosas y laicas y semejanza entre las escuelas religiosas en relación a la forma como el cuerpo es abordado.

Palabras clave: Análisis del discurso. Educación sexual. Escuelas de primer grado. Foucault. 
Este artigo constitui um relato de pesquisa realizada no decorrer do ano 2005, com o objetivo de investigar como o discurso sobre a educação sexual é produzido nas escolas religiosas e laicas na contemporaneidade na cidade de Fortaleza. Para isso, investigamos as possíveis diferenças entre essas escolas bem como o dispositivo de poder-saberprazer existente nos discursos analisados. Ademais, buscamos articular as orientações sexuais presentes nos Parâmetros Curriculares Nacionais com os discursos estabelecidos nas escolas pesquisadas.

A discussão sobre a inclusão da educação sexual nas escolas não é uma temática recente e menos ainda consensual, e gera embates no que se refere aos diversos modos de se abordar essa questão nas instituições escolares. Nesse sentido, com o intuito de orientar as escolas na revisão e na elaboração de suas propostas curriculares, o Ministério da Educação e Cultura - MEC elaborou, em 1998, os Parâmetros Curriculares Nacionais (PCN). Esse documento apresenta referências nacionais para o sistema educacional e ressalta a importância de se construir ações específicas para cada localidade, de modo a possibilitar aos jovens o acesso ao conjunto de conhecimentos socialmente elaborados e reconhecidos como necessários ao exercício da cidadania.

Nesta pesquisa, tomamos como base os PCN do ensino fundamental II apenas no tocante ao tema transversal da orientação sexual. Desde já, antecipamos que esse documento traz um olhar complexo sobre a sexualidade, considerando-a em suas dimensões biológica, psíquica e sociocultural, além de fazer uma análise sobre sua implicação política. Antecipando também elementos de nossa investigação documental preliminar sobre a temática da educação sexual, contextualizamos nosso interesse pelo tema, mencionando que a atual prefeita de Fortaleza apresentou, em seu projeto de governo, a proposta de se criar uma lei de "inclusão, de acordo com os Parâmetros Curriculares Nacionais, na grade curricular das escolas municipais, da disciplina educação sexual, com conteúdo programático positivo sobre as homossexualidades e os direitos humanos da população GLBT" (Coligação Fortaleza Amada, 2004, p. 49). Ainda Altmann (2001), Louro (2001), Ribeiro, Souza e Souza (2004) realizaram estudos que enriqueceram e renovaram os conhecimentos já existentes sobre o tema educação sexual. Esses trabalhos mostram como a orientação sexual é ensinada no contexto escolar e como o discurso da sexualidade influencia na visão corporal e sexual dos alunos, na perspectiva foucaultiana. Não foi encontrado, porém, nenhum estudo realizado em Fortaleza que tivesse utilizado diretores e coordenadores pedagógicos das escolas como sujeitos da pesquisa. Desse modo, a inclusão da orientação sexual no currículo escolar no ensino fundamental II como tema transversal dos PCN bem como os estudos nacionais existentes conferem ao nosso estudo relevância e atualidade.

Devido às possíveis influências religiosas, políticas e leigas presentes nos diversos discursos produzidos nas escolas acerca do tema da orientação sexual, consideramos pertinente estudá-los à luz de uma perspectiva foucaultiana, posto que esta enfoca as produções de discurso, investigando as relações de poder que perpassam seus enunciados bem como seu poder de disciplinamento social. Guiados por essa perspectiva epistemológica, apresentamos, a partir de nossas interpretações sobre os discursos proferidos, os possíveis mecanismos de poder utilizados para promover o disciplinamento social nas escolas em estudo, revelando o que Foucault (2005b) denominou dispositivo da sexualidade. 


\section{O Dispositivo da Sexualidade em Foucault}

O dispositivo da sexualidade está contido em uma concepção mais ampla no conceito de dispositivo desenvolvido por Foucault, sendo este composto por um conjunto de elementos heterogêneos, que, proferidos ou não, são constituídos por instituições, enunciados científicos e proposições filosóficas. Segundo Foucault (2005a), a relação existente entre esses elementos define um discurso que pode aparecer explicitamente no programa de uma instituição ou, ao contrário, implicitamente, na forma de um elemento que mascara ou justifica uma prática não revelada desta. Essa prática pode, também, ser reinterpretada através desse discurso, de modo a criar uma nova concepção racional sobre a mesma.

O autor entende, ainda, o dispositivo da sexualidade como "um tipo de formação que, em um determinado momento histórico, teve como função principal responder a uma urgência. $\mathrm{O}$ dispositivo tem, portanto, uma função estratégica dominante" (Foucault, 2005a, p. 244). O modo de funcionamento desse dispositivo se daria da seguinte forma:

O poder sobre o sexo se exerceria do mesmo modo em todos os níveis. De alto a baixo, em suas decisões globais como em suas intervenções capilares, não importando os aparelhos ou instituições em que se apóie, agiria de maneira uniforme e maciça, funcionaria de acordo com as engrenagens simples e infinitamente reproduzidas da lei, da interdição e da censura: do Estado à família, do príncipe ao pai, do tribunal a quinquilharias das punições quotidianas, das instâncias da dominação social às estruturas constitutivas do próprio sujeito, encontrar-se-ia, em escalas diferentes, apenas uma forma geral de poder. (Foucault, 2005b, p. 82)

É válido salientar que a concepção de sexo na obra foucaultiana tem uma conotação própria. Para ele, tal noção foi criada pelo dispositivo da sexualidade, havendo anteriormente apenas uma referência ao corpo, aos órgãos sexuais e às relações de aliança (Foucault, 2005a). Posteriormente, o sexo se transformou em objeto de verdade e falsidade, tornando essas realidades úteis ou perigosas, preciosas ou temidas (Foucault, 2005b).

De acordo com Foucault, o controle disciplinar sobre a sexualidade não se daria unicamente através de mecanismos negativos (repressões, proibições, censuras, negações) do sexo, mas sim, por meio da incitação ao discurso sobre este, o que promoveria uma produção de saber acerca da sexualidade. Através da proliferação desse discurso, o saber sobre o sexo iria construir-se e legitimar-se em uma sociedade ocidental, sequiosa de um saber verdadeiro. Esse saber foi constituído por meio do mecanismo da confissão, e foi inicialmente utilizado pelas instituições religiosas e, posteriormente, por instituições científicas como a Medicina, a partir do qual se tornou possível o conhecimento sobre o prazer dos indivíduos. Dessa maneira, foi possível a formulação de uma ordem classificatória e normativa que determinava um padrão de conduta sexual.

A concepção foucaultiana de poder corresponde a uma teia de relações relativamente hierarquizadas e organizadas, na qual o poder não parte de um centro para as demais regiões, mas difunde-se por todas as direções, atingindo a totalidade dos indivíduos. Dessa maneira, o que existe de fato são as estratégias de poder, que não seriam concebidas por um sujeito definido (Foucault, 2005a).

Atentos a essas apreciações, investigamos, nos discursos analisados, as possíveis formas de existência e funcionamento do dispositivo 
da sexualidade contidas na prática da educação sexual nas escolas, sabendo-as intimamente relacionadas às relações de poder que permeiam essa prática.

\section{Os caminhos das Análises dos Sentidos Produzidos: Um Percurso Metodológico}

Os sujeitos da nossa pesquisa foram os profissionais da direção e da coordenação pedagógica do ensino fundamental II de quatro escolas de Fortaleza: duas laicas - uma pública e outra particular - e duas religiosas uma católica filantrópica e uma protestante particular. Optamos por entrevistar os diretores e os coordenadores pedagógicos das escolas supracitadas por acreditarmos que ambos possuem conhecimento acerca das visões de mundo e de homem que a escola, da qual são representantes, pretende transmitir aos seus alunos. Acreditamos, ainda, que tais valores estejam inseridos na grade curricular, que é construída, também, pelos coordenadores pedagógicos. Sete entrevistas foram realizadas, sendo três com os diretores e quatro com os coordenadores pedagógicos de cada escola utilizada como fonte de dados. Para conferir maior segurança quanto ao sigilo das identidades dos entrevistados, empregamos as iniciais de nomes fictícios para as citações de suas falas. As entrevistas foram gravadas em áudio, com a permissão dos participantes, a fim de não perdermos nenhum conteúdo proferido nas falas.

Nossa interpretação foi fundamentada em uma perspectiva construcionista segundo o método elaborado por Spink e Lima (1999): análise de produção de sentidos. Nesta, os sentidos são forjados a partir das construções históricas e culturais que compõem a subjetividade humana e dos acontecimentos cotidianos, com suas diferentes implicações para a vida de cada pessoa. Em uma situação investigativa, como no caso de uma entrevista, o participante reconstrói os sentidos anteriormente produzidos ao pensar e falar sobre determinado tema e o pesquisador refaz esses sentidos ao interpretar as falas dos participantes. Adotamos um enfoque qualitativo, a fim de compreender os processos envolvidos na formação discursiva produzida pelos profissionais entrevistados em relação à educação sexual veiculada nas escolas.

Spink \& Lima compreendem que explicitar os passos da interpretação é uma estratégia que fornece rigor e visibilidade à pesquisa qualitativa. O conceito de rigor adotado prescinde de ser subsumido à órbita das qualidades da replicabilidade, fidedignidade e generalidade, fiéis ao modelo científico empirista. Para elas, rigor científico diz respeito ao compromisso do pesquisador em "... explicitar os passos da análise e da interpretação de modo a propiciar o diálogo" (Spink \& Lima, 1999, p. 102).

Realizamos entrevistas semiestruturadas, utilizando um roteiro norteador e não perguntas fechadas, para sermos coerentes com a perspectiva do construcionismo social, uma vez que esta considera que as produções discursivas originadas no momento da entrevista sejam novos sentidos construídos pelos entrevistados. O roteiro foi constituído por seis temas que surgiram a partir da leitura do referencial teórico e dos objetivos desta pesquisa: concepção de educação sexual, espaços de veiculação de educação sexual presentes na escola, forma de abordagem do corpo, relações entre o projeto político pedagógico da escola e os PCN, forma de abordagem dos temas transversais e presença da temática da religião.

Após a realização das entrevistas, transcrevemos cada uma e, conforme orientam Spink e Lima (1999), elaboramos os 
mapas de associação de ideias para auxiliarem no processo interpretativo, sistematizando o procedimento de análise. Antes de construílos, realizamos uma leitura flutuante de cada entrevista e, posteriormente, distribuímos seus conteúdos nos mapas de associação de ideias, obedecendo à ordem cronológica das falas; depois, apresentamos as perguntas dos entrevistadores, com a finalidade de contextualizar as respostas dadas e de dar visibilidade ao diálogo.

Foram construídos, ao todo, 32 mapas, constituídos de categorias e subcategorias elaboradas a partir da articulação entre os nossos objetivos, o roteiro das entrevistas, as falas dos entrevistados e o nosso referencial teórico. Cada mapa se referia a uma entrevista e apresentava suas respectivas categorias e subcategorias. Em concepção de educação sexual, constavam: conteúdos de ordem preventiva, conteúdos de ordem valorativa e a quem cabe falar sobre educação sexual. Para a categoria espaços de veiculação da educação sexual, as subcategorias foram: espaço formal, espaço informal e espaço de formação dos professores. Em como o corpo é abordado, as subcategorias foram: biologicamente e subjetivamente. E, por fim, a categoria linguagem em torno da sexualidade foi dividida em: como legitimadora do saber e como mecanismo de censura.

Em todos os mapas, repetem-se duas colunas: a primeira, intitulada entrevistador, apresenta a pergunta deste, enquanto a segunda, intitulada primeiras associações, traz as primeiras falas dos entrevistados sobre cada categoria, com a finalidade de destacá-las. As demais colunas diversificamse de um mapa para o outro em função de suas diferentes categorias e subcategorias formadoras. Os discursos foram analisados e interpretados tendo como embasamento teórico as ideias foucaultianas acerca dos dispositivos de saber-poder-prazer. Ademais, buscamos realizar uma articulação entre esses discursos e as diretrizes dos PCN (1998) no que se refere à orientação sexual para o ensino fundamental II.

\section{Os resultados de uma interpretação: Os sentidos produzidos}

Os resultados desta pesquisa referem-se à articulação entre o saber teórico e o conteúdo empírico investigado. Desse modo, estruturamos nossa discussão em torno das categorias estabelecidas no decorrer de nossa análise, ressaltando o diálogo com os sujeitos entrevistados e interpretando os sentidos a partir das falas transcritas, a fim de obter melhor sistematização e compreensão de nossas reflexões. É válido mencionar que não pretendemos, aqui, generalizar nenhum dos resultados obtidos nas análises realizadas, posto que nossas discussões refletem uma localização geográfica e temporal bem delimitada.

\section{Quanto à concepção de educação sexual:}

Percebemos que todos os entrevistados atribuíram grande relevância à abordagem da educação sexual nas escolas, ressaltando a importância de se promover a veiculação desse tema nesses locais. A temática da educação sexual apareceu intrinsecamente atrelada aos assuntos de gravidez precoce, métodos contraceptivos, doenças sexualmente transmissíveis - DSTs -, à questão do namoro dentro da escola e do ficar (gíria utilizada na atualidade, pelos adolescentes, para fazer referência a um tipo de relacionamento sem compromisso e de curto período de duração). Contudo, observamos uma diferenciação no tocante à forma de tratamento dos conteúdos 
a partir de uma perspectiva valorativa e de outra preventiva acerca da sexualidade. Percebemos certa homogeneidade entre os discursos das escolas religiosas, nas quais verificamos a necessidade de se incutir valores cristãos nas práticas de ensino.

Observamos, ainda, que essas escolas recorrem frequentemente ao dispositivo da confissão, segundo o qual os sujeitos se confessam diante de uma "instância que requer a confissão, impõe-na, avalia-a e intervém para julgar, punir, perdoar, consolar, reconciliar" (Foucault, 2005b, p. 61). Nesse sentido, coloca-se o sexo em discurso com o intuito de se controlar, de se gerenciar as práticas sexuais, bem como de se produzir um saber acerca da sexualidade que teria $o$ estatuto de saber verdadeiro. A fala de $\mathbf{X}$., diretora da escola católica, demonstra a utilização desse dispositivo:

Então, a gente acompanha as meninas, a gente cria um clima de amizade, onde elas partilham conosco os grandes amores, os grandes relacionamentos, as paixões unilaterais... E eles partilham muito isso com a gente. E a gente faz uma colocação com eles.

Dessa forma, uma ordem positiva e produtiva se sobrepõe a uma ordem repressiva e negativa, que se utiliza de proibições, sanções e restrições. Tal superposição pode ser observada na fala de $\mathbf{Z}$., coordenadora pedagógica da escola católica: "Mas a gente conversa, a gente nunca briga, nunca diz que é feio, que é errado, que... é... que é pecado, que eles não podem, que a escola não foi feita para namorar. Mas a gente conversa".

Entretanto, observamos o discurso repressivo presente na fala do entrevistado da mesma instituição, o que demonstra que essas ordens não são autoexcludentes. Z., coordenadora pedagógica da escola católica, afirma: "Então a gente tenta de todas as formas inibir esse namoro na escola... Conversar e tentar conscientizar que não é certo tá fazendo esses, essas coisas dentro da escola, a questão do namoro dentro da escola".

Nesse sentido, vai-se produzindo e reproduzindo, nas escolas religiosas investigadas, um saber, uma concepção de educação sexual que prioriza questões relacionadas à preservação do corpo, à abstinência sexual, à virgindade. É válido salientar que tais aspectos são enfatizados mesmo ao se tratar dos métodos contraceptivos ou preventivos de DSTs. Desse modo, as escolas religiosas investigadas priorizam o método da abstinência em relação ao método do sexo seguro (neste trabalho, concebido como a prática responsável do sexo com a utilização de métodos preservativos e contraceptivos). Além disso, estabelece-se um padrão normal que define uma época certa ou mais adequada para se vivenciar a sexualidade, que seria somente após o casamento. Esse discurso pode ser observado nas seguintes falas:

E a gente, quando a gente conversa sobre a sexualidade, a gente tenta colocar nessa espera de exercer a sexualidade, depois que tiverem mais maduras, valores cristãos, como é... é... a pessoa se guardar, porque se guardar, porque é legal. (X., diretora da escola católica). $(\mathrm{O}$ sexo) é uma coisa normal para um casal, para um casamento; na realidade, nós não somos a favor de uma relação sexual fora do casamento... Agora, como escola, nós aconselhamos que eles (os alunos) aguardem, tem tantas outras coisas que eles podem fazer, se dedicar a um esporte (W., diretora da escola protestante). 
Percebemos, ainda, que as práticas nas escolas religiosas estudadas são bastante influenciadas pelo discurso da Igreja ou da própria Bíblia, seja no colégio filantrópico, seja no particular. Vejamos: K., coordenadora da escola protestante: "Mas a gente deixa claro o que vem na Bíblia, principalmente a Bíblia, o colégio é evangélico, então a Bíblia evangélica nos deixa até uma base assim: quem ama, espera".

Por outro lado, as escolas laicas não seguem essa mesma orientação. Nesses locais, prioriza-se a prática do sexo seguro com o uso de preservativos e contraceptivos, e não há uma política institucional dirigida à inculcação de valores morais cristãos que orientam a vida sexual das pessoas.

A orientação da prática do sexo seguro é abordada ainda com mais rigor na escola pública, que é bastante influenciada pelas campanhas governamentais de controle de DSTs, de natalidade. Estas visam, dentre outros fatores, às medidas higienistas, ao recenseamento da população e à diminuição dos custos do Governo em relação a esses problemas. Essas ações governamentais podem ser percebidas neste depoimento:

\begin{abstract}
O tema educação sexual se faz presente na semana cultural do colégio, através da implementação do Projeto Amor à Vida, do Governo do Estado, que tematiza a educação sexual e o uso de drogas. Uma orientadora educacional trata da educação sexual com os alunos, levando textos e vídeos. Há uma sala para o trabalho com os pais e alunos e existem trabalhos isolados dos professores em suas disciplinas (H., diretora da escola pública laica).
\end{abstract}

Já a escola particular laica aparentemente não possui suas práticas atreladas nem às campanhas governamentais nem às instituições religiosas. Observa-se, nessas escolas, uma preocupação maior em atender os interesses dos pais ou responsáveis pelos seus alunos, uma vez que são eles que pagam pelos serviços da escola. Pareceu-nos, ainda, que tal fato contribui para a orientação da educação sexual vigente nessa escola, o que podemos vislumbrar por meio do discurso de

A., coordenadora da escola laica particular: "Mas aqui é uma casa de educação, e a gente convive com muitos pais que não per... que não gostam de ver seus filhos pequenos vendo esse tipo de coisa (beijos, abraços...), então a gente evita".

Observamos, ainda, que as ações tomadas por todas as escolas estudadas têm se afastado de uma lógica punitiva. Busca-se, então, trabalhar valores e comportamentos, com o intuito de impedir a ocorrência de certas atitudes não desejáveis. Nesse sentido, esses posicionamentos vão sendo trabalhados de forma bastante discreta, podendo-se observar, principalmente nas escolas religiosas, a sutileza com que certos conteúdos vão sendo inculcados e transmitidos para os alunos, a fim de que correspondam às expectativas das instituições. Observamos esse discurso em Z., coordenadora pedagógica da escola católica:

\footnotetext{
Fui falar para ela que ela não deveria trazer, que a camisinha, a vida sexual dela, era uma coisa particular dela, que ela não precisava tá trazendo... mas jamais em forma de carão: 'que coisa feia', 'isso é feio, você vai acabar engravidando', não, jamais. Então os professores respeitam muito. E, quando tem alguma coisa que foge do controle deles, eles passam para a coordenação e direção.... E a gente consegue passar a mensagem que a gente quer.
}

Percebemos semelhança entre as práticas expostas no depoimento da coordenadora da escola católica e o que é proposto nos PCN (1998), o que pode ser elucidado na citação a seguir: 
Quando a questão da sexualidade é tomada como algo sério a ser esclarecido, compreendido e estudado, tende a modificar a relação agitada dos adolescentes com o tema. Vão perdendo progressivamente sentido os desenhos de órgãos genitais nas carteiras, paredes e banheiros da escola, como atitudes provocativas e exibicionistas de sensualidade exacerbada ou as tentativas de escandalizar os adultos. (p. 301)

Dessa maneira, essas orientações são capilarizadas, alcançando-se grande número de indivíduos ao mesmo tempo em que se trabalha cada um em sua singularidade. Para tanto, utiliza-se, inclusive, de recursos lúdicos, tais como jogos e gincanas, a fim de facilitar, de tornar mais leve a colocação de certos aspectos em discussão, como a sexualidade. Discurso de $\mathbf{X}$., diretora da escola católica: "É um trabalho de orientação, a gente vai além do currículo normal. A gente tem projetos, trabalha com adolescentes específicos na área de educação sexual".

Percebe-se, assim, que a sutileza desse inculcamento pode contribuir para uma interiorização do olhar do outro, do olhar da instituição:

Já o olhar vai exigir muito pouca despesa. Sem necessitar de armas, violências físicas, coações materiais. Apenas um olhar. Um olhar que vigia e que cada um, sentindo-o pesar sobre si, acabará por interiorizar, a ponto de observar a si mesmo; sendo assim, cada um exercerá essa vigilância sobre e contra si mesmo. Fórmula maravilhosa: um poder contínuo e, ao final de contas, irrisório. (Foucault, 2005a, p. 218).

\section{Quanto aos espaços de veiculação da educação sexual:}

Em seu percurso sobre a história da sexualidade, Foucault (2005b) nos mostra que, a partir do fim do século XVI, ocorre, ao invés de uma restrição, uma explosão discursiva acerca do sexo. De acordo com o autor, por volta do século XVIII, a incitação ao discurso sobre a sexualidade adquire novos espaços, sendo ele proferido, inclusive, na política e na economia. Os estabelecimentos educacionais dessa época também tratavam do sexo. Segundo Foucault, bastaria atentar para a arquitetura desses locais para que isso logo fosse percebido. A partir disso, constituir-se-ia "toda uma literatura... em torno do colegial e de seu sexo" (p. 31). Posteriormente, a Medicina, a psiquiatria, a demografia, a biologia, a Psicologia e inúmeras outras áreas também colocaram a sexualidade em foco, demonstrando que as sociedades modernas se preocuparam bastante em falar do sexo, valorizando-o, contudo, como um segredo. A existência desse segredo e a sua consequente necessidade de revelação exigiam a formulação de um saber que contemplasse essas questões.

Em relação aos espaços destinados à veiculação da educação sexual nas escolas estudadas, percebemos que todas se utilizam das disciplinas de ciências ou biologia para a transmissão de conhecimentos relativos a esse conteúdo. Essas matérias escolares possuem seu foco voltado para os aspectos anatômicos e fisiológicos do corpo humano, não abordando questões referentes à subjetividade (pensamentos, sentimentos e emoções) presentes nesses. Percebemos, com isso, um discurso enunciado (dito) e outro, oculto (não dito), e que este, segundo Foucault (2007), pode ser inferido e interpretado também através das condições ambientais que o impediram de emergir. Isso significa que o fato de o aspecto subjetivo da sexualidade não ser abordado na escola não impede que os alunos o vivenciem e 
Em seu percurso sobre a história da sexualidade, Foucault (2005b) nos mostra que, a partir do fim do século XVI, ocorre, ao invés de uma restrição, uma explosão discursiva acerca do sexo. o interpretem, levando em consideração, em maior ou menor grau, as sensações, sentimentos e pensamentos envolvidos nessa prática. As escolas mencionaram também a organização de palestras e seminários voltados para a abordagem da educação sexual. Esses momentos eram, muitas vezes, organizados em parceria com entidades convidadas, mais especializadas para transmitir esse saber.

Já as escolas religiosas utilizam, além dos espaços mencionados acima, aulas de religião ou de orientação cristã para a veiculação de certos conteúdos relacionados à educação sexual. Nestes, são trabalhados valores cristãos referentes à preservação e ao respeito ao corpo e à virgindade, dentre outros. Ademais, essas escolas mencionaram a realização de gincanas, jogos e semanas culturais com o intuito de tratar esse assunto de forma lúdica. Além desses espaços formais, foi-nos relatada a existência de outros momentos nos quais é também trabalhada a educação sexual, ainda que de forma indireta. Trata-se das conversas informais que ocorrem, segundo relatado, principalmente na ocasião de emergência de problemas com os alunos. Nessas conversas, observa-se uma incitação aos discursos sobre o sexo, através das quais os indivíduos falam de si, de sua sexualidade. Posteriormente, essas conversas informais contribuem para a promoção de consequências diretas sobre as suas práticas, uma vez que é a partir dessas informações que se estabelecem os exercícios de controle, conhecimento e administração da sexualidade. Percebemos a incitação sutil ao discurso sobre o sexo nas seguintes falas:

\section{K., coordenadora pedagógica da escola protestante:}

"E muito mais ouvindo, deixando eles falarem do que a gente falando pra_eles: 'Que vocês estão pensando?' E levando-os a fazer uma reflexão disso", e A., coordenadora pedagógica da escola particular laica: " $A$ gente sempre tem também muito cuidado e conversa com os alunos, com aqueles que a gente sabe que namoram, né? Mas, sempre em conversas mais informais"

Como pudemos observar, essa colocação do sexo em pauta ocorre tanto nos espaços formais quanto nos informais das escolas estudadas. Percebemos, assim, a proliferação dos discursos sobre a sexualidade, buscando-se, como já mencionado, não somente o controle das práticas mas também, e principalmente, a produção de saberes e concepções acerca delas. No entanto, não são todas as pessoas que estão autorizadas a veicular e a enunciar esse saber oficial. Somente professores, coordenadores, diretores, orientadores ou convidados da escola são considerados capacitados para tal função, o que acaba por implicar relações hierarquizadas de saber dentro das próprias escolas.

As escolas utilizam também mecanismos não tão sutis na prática do controle disciplinar. Nas falas dos entrevistados, foi citada a existência de monitores na hora do recreio, de vigilância no acesso aos banheiros, a fim de impedir que a prática sexual fosse exercida nesses espaços. Podemos observar esse controle em Z., coordenadora pedagógica da escola católica: "Mas a gente fica muito atento, a gente diz que não pode, que namoro tem que ser em casa, com os pais vendo, com a autorização dos pais. Então a gente fica muito, muito atento, a gente não deixa", e em A., coordenadora pedagógica da escola particular laica: "A gente tá sempre... no recreio tem sempre gente de plantão, tem sempre coordenadores, auxiliares de plantão para que evite qualquer excesso, né?"

A escola surge, então, como um local legítimo de produção e veiculação de um saber verdadeiro sobre a sexualidade, mas não 
como um espaço de prática desta. De acordo com a fala acima, a sexualidade teria, assim, um local certo para ser exercida: a casa dos pais! No entanto, conforme os PCN:

A sexualidade no espaço escolar não se inscreve apenas em portas de banheiros, muros e paredes. Ela "invade" a escola por meio das atitudes dos alunos em sala de aula e da convivência social entre eles. Por vezes a escola realiza o pedido, impossível de ser atendido, de que os alunos deixem sua sexualidade fora dela. (PCN, 1998, p. 292)

\section{Quanto à forma de se abordar o corpo:}

Segundo Foucault (2005b), há uma diferença quanto à forma de abordar o corpo antes e depois do séc. XVII. Antes, a ele se ligava a ideia de morte, visto que os reis tinham o poder de levá-la aos seus súditos, mandandoos para as guerras. Isso acontecia quando sentiam suas vidas ameaçadas, ou seja, havia toda uma política do sangue que envolvia o valor do corpo da nobreza. A partir do século XVII, a burguesia, em sua ascendência social, passou a enfatizar no físico a possibilidade de vida, ou seja, de reprodução, de higiene, de saúde, de prazer, enfim, criou para ele o sentido de sexo: o corpo anatômico propenso à morte se transformou em um corpo sexual, favorável à vitalidade. Contudo, a abordagem desse físico tomara duas formas: uma que via “(o) corpo como máquina: no seu adestramento, na extorsão de suas forças, no crescimento paralelo de sua utilidade e docilidade, na sua integração em sistemas de controle eficazes e econômicos" (p.131), e outra no corpo-espécie,

no corpo transpassado pela mecânica do ser vivo e como suporte dos processos biológicos: a proliferação, os nascimentos e a mortalidade, o nível de saúde, a duração da vida, a longevidade, com todas as condições que podem fazê-lo variar; tais processos são assumidos mediante toda uma espécie de intervenção e controles reguladores: uma biopolítica da população. ( p.131)

Observamos, bastante presente nas falas dos diferentes entrevistados, o corpo discutido como corpo-espécie. Embora houvesse uma clara orientação dos $\mathrm{PCN}$ para tratá-lo como propenso ao prazer, houve, ainda, por parte das escolas religiosas, uma empreitada para submeter esse corpo às doutrinas cristãs. Percebemos, nesses mesmos colégios, uma ascese moral no ensino formal de valores religiosos sobre o físico, tal como a virgindade, inclusive através de jargões como: "quem ama, espera", e a repressão informal das concupiscências. Contudo, o que nos chamou a atenção foi a insistência dos entrevistados em justificar esse tipo de ensino através do sentido da valorização e da preservação do corpo como responsabilidade pelo mesmo, ou seja, o ensino remete à noção de corpo-espécie com funções naturais, negando a subjetividade dos desejos. Portanto, ainda que predominasse um enunciado religioso, havia também uma influência dos discursos modernos sobre o físico, vista em Z., coordenadora pedagógica da escola católica: "Eles falam não só da mudança do corpo, mas como pode acontecer uma gravidez, como eles vão ser responsáveis, como a vida vai mudar se acontecer uma gravidez."

\section{E em K., coordenadora pedagógica da escola protestante:}

"Isso a gente fala (de virgindade), porque tem na Bíblia, mas muito mais pra preservar o corpo no sentido de eu ter consciência daquele corpo e qualquer atitude que eu tome depois, sou eu que vou estar comigo mesma."

Fala-se do corpo como um aparelho mecânico que tem lubrificantes, mecanismos biológicos de ereção: tudo para desmistificar o pornográfico. Na fala a seguir, podemos observar o duplo tratamento dado ao físico, 
tanto como corpo-espécie, como corpomáquina:

É... aula que tem o corpo humano, que explica o funcionamento do aparelho reprodutor feminino, masculino, como funciona, com muita naturalidade. $\mathrm{E}$ quando eles usam alguma brincadeira, que passa pra pornografia, a instrução é de não se escandalizar e de retomar o discurso de que não existe nada feio, nada de imoral no corpo da gente... nós temos organizado feira de ciências onde se estuda todo o corpo... então eles falam com muita simplicidade sobre o pênis, os testículos, a função, o que faz o pênis ficar ereto biologicamente, a questão da lubrificação da vagina, porque isso acontece, eles falam com muita tranquilidade sobre isso, e, com isso, a gente desmistifica a questão de associar o corpo humano com a pornografia e com o tabu da coisa feia, a gente tenta lidar com muita naturalidade com o corpo humano. (Z., diretora da escola católica)

Já nas duas escolas laicas, percebemos a pouca importância atribuída ao ensino de conteúdos subjetivos ou simbólicos sobre o corpo. Este é tratado prioritariamente dentro das disciplinas de ciências e biologia na sua forma anatômica e reprodutiva. Observamos, também, tanto nas escolas laicas quanto religiosas, um controle informal das concupiscências, sendo este justificado pela vontade dos pais dos alunos matriculados, mostrando o caráter disciplinador e normatizador da escola. Tal ato pode ser mostrado na fala a seguir:

A gente já teve, na sétima série, uma aluna, que já saiu da escola no mês passado, com essa questão da sexualidade muito acirrada, muito aflorada, que a gente precisou mesmo trabalhar isso aí com ela, mas acabou sem dar certo, porque ela era uma aluna só de... Que assim a gente não aprofunda, não entra como disciplina, não aprofunda e acabou sem dar certo e ela teve que sair. (O., coordenadora

pedagógica da escola laica pública)
Para a escola pública laica, são ofertados alguns projetos educativos governamentais e de ONGs, que tratam o corpo de forma mais simbólica, ou seja, menos conservadora. Esses projetos prezam o uso de termos populares, da forma como são empregados pela população, sendo, muitas vezes, considerados chulos pelas entrevistadas.

Notamos, também, uma grande distância, dentro das escolas religiosas, em relação aos princípios estabelecidos pelos $\mathrm{PCN}$, uma vez que elas primam pela castidade, sendo a orientação sexual transmitida diretivamente em defesa da abstinência sexual como recurso de prevenção e preservação do corpo. $\mathrm{Na}$ escola protestante, esse distanciamento pôde ser percebido, ainda, na fala da diretora, a seguir, quanto à liberdade de escolha da orientação sexual:

\begin{abstract}
Por exemplo, enquanto eu digo assim que o homossexualismo é uma questão de opção, como cristãos, nós não achamos que seja uma questão de opção, é uma questão de um valor assim cristão que você formula, que você questiona e acha que é algo que não é assim tão normal e uma questão de opção, porque, inclusive, achamos que a própria educação está ligada a isso. (W., diretora da escola protestante)
\end{abstract}

Por outro lado, a escola laica pública se aproxima do que é orientado pelos $\mathrm{PCN}$, que primam pelo exercício do sexo seguro, apoiam a prática sexual dos alunos, concebendo-a como saudável, e tentam educar contra os tabus e os preconceitos da expressão homossexual. Na escola laica particular, fora a abordagem anatômica do corpo nas disciplinas de ciências, não observamos a abordagem do corpo sexual, talvez porque, nessa escola, o que fica evidente é a concepção do corpo como máquina. Porém, essa concepção não se presentifica nos discursos, mas sim, na 
normalização, na disciplina, no empenho para formar corpos dóceis, com a única função de se inserir no mercado de trabalho e de servir a uma economia. Tal ponto de vista se justifica, já que estamos a falar de uma escola que adota a disciplina como método de se passar em vestibulares, fazendo-se, assim, reconhecida. Podemos, então, inferir que, nos discursos dessa escola, é configurado o não dito sobre o corpo.

\section{Quanto à linguagem em torno da sexualidade:}

No livro História da Sexualidade-I, Foucault (2005b) nos apresenta dois procedimentos históricos de produção da verdade sobre o sexo: um seria o da ars erotica, na qual a verdade do sexo implica se transmitir tradicionalmente, pelos mestres, os segredos do prazer, que assim deveriam se manter para não perder sua eficácia e virtude. Tudo giraria em torno do "domínio absoluto do corpo, gozo excepcional, esquecimento do tempo e dos limites, elixir de longa vida, exílio da morte e de suas ameaças" (p. 57).

O outro procedimento histórico seria o da scientia sexualis, que, ao contrário do primeiro, utiliza a técnica da confissão tanto nas religiões quanto nas ciências, extorquindo das pessoas tudo sobre seu sexo e, posteriormente, colocando esse saber em uma ordem utilitária que nega o sexo pelo simples prazer. Dessa forma, encontram-se outras utilidades, e forma-se uma rede de especulações e planificações sobre o sexo. Ao contrário da centralidade no prazer da ars erotica, o discurso científico projeta na sociedade saberes utilitários sobre o sexo através dos ditos sobre a reprodução da espécie, o controle da natalidade, a higienização, etc., tentando criar uma forma neutra de discursar que vai contra o erotismo. Nesse procedimento, havia as pessoas certas para falar de sexo, ou seja, as pessoas da ciência. Formava-se, portanto, uma rede de peritos que levavam a verdade do sexo às pessoas: médicos, psicólogos, psicanalistas, sociólogos, etc., dizendo o que fazer, como fazer e quando fazer, de modo que o sexo fosse economicamente útil e viável politicamente.

Notamos, nas falas dos entrevistados das diferentes escolas abordadas, a importância atribuída à linguagem em que devem ser passados os conteúdos sobre educação sexual. Em todas elas, percebemos o acolhimento de uma linguagem científica que neutralizasse o teor erótico dos assuntos abordados e que fosse capaz de falar sobre sexo sem incitar o desejo que potencializasse uma prática sexual. Na fala da coordenadora da escola pública, que participou também, junto à então diretora, da entrevista, observamos a defesa de que os conteúdos da educação sexual deveriam ser repassados em uma linguagem científica, dentro dos termos da biologia, segundo ela, de forma não vulgar. Tal argumento pode ser mostrado no seguinte discurso:

Quando a palestra é muito alta, a gente, eles já dizem: não, a gente vai ficar só com o terceiro ano. Porque esse tipo de linguagem, nós tivemos uma aqui... Ele vinha vender uns livros de saúde e tudo, só que ele dava palestra, e ele usou uns termos muito chulos, sabe? Assim muito do meio da rua, nada científico, mas ele estava todo vestido de branco. (O., coordenadora pedagógica da escola laica pública)

Diferentemente desse depoimento, o trabalho de orientação sexual proposto pelos PCN visa à reflexão acerca dos tabus e preconceitos em relação à sexualidade, afirmando ser ela algo ligado ao prazer e à vida. Desse modo, presumimos, segundo essa orientação, que também na discussão sobre doenças sexualmente transmissíveis se 
devem enaltecer os sentidos mais profundos de cuidado e de responsabilidade para com os corpos e espíritos amantes.

Percebemos, ainda, nas escolas estudadas, a necessidade de pessoas especialistas para falar sobre assuntos relativos à vida sexual, como cita Foucault (2005b): "É preciso tentar determinar as diferentes maneiras de não dizer, como são distribuídos os que podem e os que não podem falar, que tipo de discurso é autorizado ou que forma de discrição é exigida a uns e outros" (p.30).

Tal aspecto pode ser elucidado nas seguintes falas: A., coordenadora pedagógica da escola particular laica: "Normalmente, a gente conversa, mas eles são encaminhados pra ela (psicóloga). É assim até porque ela tem uma abordagem mais específica sobre $o$ assunto" (namoro na escola).

W., diretora da escola protestante: Agora é dado através do educador, dos profissionais que são chamados pra ter palestras com eles. Então, a gente convida enfermeiros, médicos, pessoas mais aprofundadas nessa área (sexualidade).

Observamos uma preocupação dos entrevistados com o uso de uma linguagem adequada à idade das crianças, o que nos fez interpretá-la como um mecanismo de censura. Segundo o depoimento de O., coordenadora pedagógica da escola pública laica:

Quando a palestra é muito alta, a gente, eles já dizem: 'não, a gente vai ficar só com o terceiro ano'. Porque, nesse tipo de linguagem, nós tivemos uma aqui que eu levei um pessoal da oitava e depois os professores se queixaram, a gente reclamou. Agora, quando chega uma palestra pra gente, a gente diz qual é o público.

\section{Considerações finais: onde chegamos}

Partindo da investigação dos discursos produzidos sobre a educação sexual nos diferentes tipos de escolas de Fortaleza particular, pública, laica e religiosa -, pudemos observar, através do choque entre os discursos sobre a educação sexual nas escolas laicas e religiosas, a presença de certa diretividade doutrinária no ensino da educação sexual nas escolas religiosas. Percebemos, também, uma diferenciação em relação à abordagem do corpo: em todas as escolas investigadas, observamos o tratamento do mesmo como organismo propenso a se reproduzir e a adoecer, havendo, portanto, o discurso da prevenção. Contudo, há uma diferença entre as formas de prevenção adotadas pelas escolas: nas religiosas, percebemos uma clara orientação para a abstinência sexual antes do casamento, enquanto, nas laicas, observamos a inexistência desse tipo de discurso, priorizando-se a prática do sexo seguro.

Ao comparar os discursos sobre a educação sexual entre as duas escolas religiosas, católica e protestante, percebemos certa homogeneidade entre elas: ambas se empenham em passar valores cristãos na educação sexual, tanto formalmente quanto informalmente. Tais escolas se esforçam, também, em suavizar o teor erótico sobre o corpo através da desmistificação e da naturalização de suas funções sexuais. Entretanto, percebemos que a escola protestante é mais diretiva ao transmitir seus conteúdos dogmáticos, ao passo que a católica o faz de forma mais sutil, principalmente a partir do dispositivo da confissão mencionado anteriormente.

Quanto à investigação dos dispositivos de poder-saber-prazer existentes nos discursos 
analisados, e tendo em vista a elasticidade com que Foucault emprega esse termo, identificamos uma diversidade na forma de aplicação desse dispositivo, na busca de um saber válido sobre a educação sexual, entre os quais citamos, inclusive, os que nos serviram como categorias de análise. Um desses dispositivos são os espaços de veiculação da educação sexual, visto que esses são oportunamente utilizados para o inculcamento de saberes sobre o sexo. Outro dispositivo é a adoção de uma linguagem técnica autorizada para falar acerca do sexo, havendo, assim, um controle sobre a verdade a ser dita. Ao mesmo tempo, percebemos a marginalização de outros saberes, como é caso do saber popular. Dessa forma, são valorizados apenas os discursos provenientes dos peritos da ciência, tais como médicos, enfermeiros, psicólogos, sociólogos e terapeutas ocupacionais, apontando, assim, a existência de pessoas legitimadas a abordar esse tema. Outro dispositivo muito utilizado, principalmente na escola católica, foi o da incitação aos discursos, que funciona como estratégia de identificação e de controle dos assuntos relativos à vida sexual dos alunos, ou seja, do dispositivo da confissão, sendo esta sutilmente realizada através de conversas informais.

Por fim, articulamos as propostas de orientações sexuais presentes nos Parâmetros Curriculares Nacionais com os discursos investigados nas escolas pesquisadas. Percebemos que os PCN (1998) trazem uma clara posição de defesa do direito do prazer e do exercício da sexualidade, pois o sexo é percebido como intrínseco à vida, defendendo uma concepção de corpo contrária à de um organismo voltado somente para a reprodução e as funções vitais. Nessa lógica, propõe a prática do sexo seguro como método de prevenção de doenças e de gravidez indesejada, procurando, também, combater tabus e preconceitos relativos a condutas sexuais moralmente recriminadas. De modo semelhante, o projeto de governo de Luizianne Lins aborda o sexo como direito do cidadão, independentemente da sua orientação sexual, ao buscar a efetivação dos direitos humanos da população GLBT. Ao contrário do que é proposto nesses dois documentos, percebemos a presença, na escola protestante, de um discurso de claro combate à liberdade da orientação sexual. Ademais, observamos, em todos os discursos das escolas estudadas, uma investida contra os excessos nos namoros e um acolhimento da concepção mecânica do corpo.

Ressaltamos, ainda, que os sentidos produzidos na análise desta pesquisa não se pretendem inquestionáveis, uma vez que são produtos de uma entre as muitas possíveis (des)construções e interpretações da realidade percebida. 


\section{Eugênia Marques de Oliveira Melo*}

Psicóloga, Especialista em Terapia Clínica Analítico - Comportamental pelo Núcleo Paradigma de Análise do Comportamento, São Paulo, SP - Brasil.

\section{Débora Pinho Arruda}

Especializanda em Teoria e Prática Junguiana pela Universidade Veiga de Almeida, Rio de Janeiro, RJ - Brasil. Psicóloga do Juizado de Violência Doméstica e Familiar contra a Mulher - Tribunal de Justiça do Ceará, Ceará, CE - Brasil.

E-mail: deborapinhoa@yahoo.com.br

\section{Helenira Fonseca de Alencar}

Psicóloga, Mestranda em Psicologia pela Universidade Federal do Ceará, Ceará, CE - Brasil.

E-mail: helenira@vol.com.br

\section{Veriana de Fátima Rodrigues Colaço}

Psicóloga, Doutora em Educação pela Universidade Federal do Rio Grande do Sul, Porto Alegre, RS - Brasil. Professora adjunta do Departamento de Psicologia da Universidade Federal do Ceará, Ceará, CE - Brasil.

E-mail:verianac@uol.com.br

* Endereço para envio de correspondência:

Alameda dos Bogaris, 69 - Quadra 30- Bairro: Cidade 2000 - Fortaleza, CE - Brasil - CEP 60190-220.

E-mail: eugenia_marques@yahoo.com.br

Recebido 20/4/2009, 1a Reformulação 17/8/2009, 2a - Reformulação 14/9/2009, Aprovado 30/9/2009.

\section{Referências}

Altmann, H.(2001). Orientação sexual nos parâmetros curriculares nacionais. Estudos Feministas, 9(2), 575-585. Recuperado em 13 de fevereiro de 2006, de http://www. scielo.br/scielo.php?script $=$ sci_arttext\&pid $=$ S0104026X200 $1000200014 \& \operatorname{lng}=$ pt\&nrm $=$ iso

Coligação Fortaleza Amada (PT e PSB). (2004). Por amor a Fortaleza: propostas para uma cidade bela, justa e democrática. Fortaleza. ( Projeto de Governo da candidata Luizianne Lins a prefeita de Fortaleza)

Foucault, M. (2005a). Microfísica do poder (21a ed.). Rio de Janeiro: Graal.

Foucault, M. (2005b). História da sexualidade 1: a vontade de saber (16a ed.). Rio de Janeiro: Graal.

Foucault, M. (2007). A arqueologia do saber (19a ed.). Rio de Janeiro: Forense Universitária.

Louro, G. L. (2001). Teoria queer: uma política pós-identitária para a educação. Revista de Estudos Feministas, 9(2), 541-553. Recuperado em 13 de fevereiro 2006, de http://www.scielo. br/scielo.php?script=sci_arttext\&pid=S0104-026X2001000 $200012 \& \operatorname{lng}=$ en\&nrm $=$ iso
Ribeiro, P. R. C., Souza, N. G. S. de, \& Souza, D. O. (2004). Sexualidade na sala de aula: pedagogias escolares de professoras das séries iniciais do ensino fundamental. Revista de Estudos Feministas. 12(1),109-129. Recuperado em 13 de fevereiro 2006, de http://www.scielo.br/scielo. php?script $=$ sci_arttext\&pid $=$ S0104-026X2004000100006 \&lng $=$ en\&nrm $=$ iso

Secretaria de Educação Fundamental. (1998). Parâmetros Curriculares Nacionais: ensino de quinta a oitava séries. Recuperado em 13 de fevereiro 2008, de ftp://ftp.fnde.gov. br/web/pcn/05_08_orientacao.pdf

Spink, M. J. P., \& Lima, H. (1999). Rigor e visibilidade: a explicitação dos passos da interpretação. In M. J. P. Spink (Ed.), Práticas discursivas e produção de sentido no cotidiano: aproximações teóricas e metodológicas (pp. 93-122). São Paulo: Cortez. 